Estudios Geológicos, 67(1)

enero-junio 2011, 21-39

ISSN: 0367-0449

doi:10.3989/egeol.40283.125

\title{
Las sucesiones sedimentarias continentales expuestas en Centinela del Mar, provincia de Buenos Aires, Argentina (Pleistoceno Inferior-Holoceno)

\author{
Continental sedimentary successions exposed in Centinela del Mar, \\ Buenos Aires, Argentina (Lower Pleistocene - Holocene)
}

M.M. Cenizo ${ }^{1,2}$

RESUMEN

Son descriptas e interpretadas las características geomorfológicas y sedimentarias de las sucesiones continentales expuestas en los acantilados litorales y sectores aledaños de la localidad Centinela del Mar. Se definen catorce litofacies, cuyas relaciones, geometría y estructuras son representadas mediante perfiles transversales y longitudinales de detalle. En el sector basal y medio del perfil fueron reconocidas facies de distinto grado de transporte y retrabajo ácueo, en tanto, en el sector superior fue identificada una secuencia de facies marinas y perilitorales correspondientes a la transgresión «Belgranense» (=Fm. Pascua), culminando la sucesión facies eólicas relictuales. Las diferentes interpretaciones históricas son ampliamente discutidas, homologándose las unidades referidas previamente con las propuestas en este trabajo. Dichas unidades se correlacionan con aquellas definidas en el esquema aloestratigráfico propuesto para el área comprendida entre Playa San Carlos y Arroyo Chapadmalal. Esto permitió reconocer para el área bajo estudio la presencia de las Aloformaciones Punta San Andrés y Arroyo Lobería (sector basal-medio y cuspidal, respectivamente). Entre estas dos entidades, se intercala una asociación de facies marinas progradantes hacia ambientes perilitorales definidas y nominadas aquí como Aloformación Centinela del Mar. Finalmente, la información aquí reunida (magnetoestratigrafía, dataciones radiométricas, correlaciones estratigráficas, etc.) permite indicar, al menos preliminarmente, que la sucesión de Centinela del Mar corresponde al intervalo Ensenadense-Lujanense (Pleistoceno Inferior-Holoceno).

Palabras clave: Litofacies, Estratigrafía, Geomorfología, Pleistoceno, Centinela del Mar, Buenos Aires, Argentina.

\begin{abstract}
In the present paper, the geomorphological and sedimentary characteristics of the continental sequences exposed on the coastal cliffs and surrounding areas of the Centinela del Mar locality are described and interpreted. Fourteen lithofacies are defined, their relation, geometry and structure are represented using transversal and longitudinal detailed profiles. In the basal and medium sector of the profile, facies of different degrees of transport and aqueous rework were recognized. In the superior sector, a succession of marine peri-coastal facies corresponding to the «Belgranense» transgression (=Fm. Pascua) were identified, ending the secuence with relictual eolic facies. The different historical interpretations are discussed, homologating the units referred previously with the ones proposed on this paper. These units are correlated with those defined in the allostratigrapic scheme proposed by other authors for the area covered between Playa San Carlos and Arroyo Chapadmalal. This allowed recognize for the area under study the presence of the Punta San Andrés and Arroyo Lobería Alloformations (basal-medium and superior sector, respectively). Between these two entities, a association of well defined progradant marine facies are found and named on this paper as Centinela del Mar Alloformation. Finally,
\end{abstract}

\footnotetext{
1 Facultad de Ciencias Exactas y Naturales, Universidad Nacional de La Pampa, Uruguay 151 (6300), Santa Rosa, La Pampa, Argentina. Email: cenizomarcos@yahoo.com.ar

2 Area Paleontología. Fundación de Historia Natural «Félix de Azara». Departamento de Ciencias Naturales y Antropología. CEBBAD - Universidad Maimónides. Valentín Virasoro 732 (C1405BDB), Ciudad Autónoma de Buenos Aires, Argentina.
} 
the information gathered here (magnetostratigraphy, radiometric dating, stratigraphic correlations, etc) indicates, at least preliminarily, that the secuence of Centinela del Mar corresponds to the EnsenadenseLujanense interval (Lower Pleistocene - Holocene).

Key words: Lithofacies, Stratigraphy, Geomorphology, Pleistocene, Centinela del Mar, Buenos Aires, Argentina.

\section{Introducción y Objetivos}

La localidad de Centinela del Mar (a partir de ahora $\left.\mathrm{CdM}, 38^{\circ} 26^{\prime} \mathrm{S}, 58^{\circ} 14^{\prime} \mathrm{O}\right)$ se encuentra ubicada al sudeste de la provincia de Buenos Aires, entre las localidades de Mar del Sur y Necochea (Fig. 1). Aquí se levanta un sector de acantilados litorales antiguamente conocidos como «Baliza Malacara» (Frenguelli, 1921) o «Barranca Malacara» (Parodi \& Parodi Bustos, 1952).

Desde los albores de las Ciencias Naturales en la Argentina, dicha localidad ha sido un relevante centro de atención tanto para paleontólogos como para arqueólogos (e.g. «túmulo de Malacara»; Torres \& Ameghino, 1913a, 1913b). Sin embargo, no existe hasta el momento consenso acerca de la correspondencia entre las unidades sedimentarias aquí presentes y los esquemas crono-bioestratigráficos y litoestratigráficos vigentes, representando $\mathrm{CdM}$ una localidad problema dentro del contexto estratigráfico regional. Esta falta de asentimiento se debió principalmente al establecimiento de correlaciones conceptualmente bioestratigráficas pero que, dado el exiguo registro faunístico, siguieron un criterio casi exclusivamente litológico (e.g. Frenguelli, 1921, 1928; Parodi \& Parodi Bustos, 1952; Kraglievich, 1959). Las primeras aproximaciones basadas en asociaciones faunísticas representativas fueron dadas a conocer por Tonni et al. (1987) y referidas a las unidades superiores de la sucesión.

De acuerdo a lo expresado anteriormente, este trabajo tiene como objetivo principal brindar un esquema estratigráfico de referencia para la descripción de las tafofaunas colectadas en dicha localidad, las cuales han sido dadas a conocer parcialmente (e.g. Scanferla et al., 2005; Cenizo \& Ibáñez, 2006; de los Reyes et al., 2006a, 2006b; Cenizo \& Agnolin, 2007; Cenizo \& de los Reyes, 2008; Bogan et al., 2009) y serán motivo de futuras publicaciones. De esta manera, los distintos esquemas estratigráficos propuestos previamente para la localidad son ampliamente discutidos y sintetizados. Por otra parte, las unidades identificadas se correlacionan tentativamente con aquellas definidas en el esquema aloestratigráfico propuesto por Zárate (1989) para el sector de acantilados comprendido entre Playa San
Carlos y el Arroyo Chapadmalal (unos $50 \mathrm{~km}$ al NE de la localidad bajo estudio). Finalmente, son resumidas las principales inferencias sedimentarias, estratigráficas y geocronológicas disponibles para la sucesión de facies presentes en los acantilados de CdM.

\section{Materiales y métodos}

Los conceptos adoptados de litofacies, sucesión de facies y asociación de facies corresponde a Reading y Levell (1996). Para la descripción de facies y procesos sedimentarios asociados es seguido principalmente el criterio de Zárate (1989) con adaptaciones a la clasificación de Miall (2000). El esquema crono-bioestratigráfico es el propuesto por Cione y Tonni (2005).

Las facies fueron descriptas objetivamente, su reconocimiento, asociación natural y jerarquía de contactos fueron determinados y discutidos durante ininterrumpidos trabajos de campo desde 2001 hasta 2010. Las unidades definidas fueron mapeadas implementando dos tipos de perfiles estratigráficos. En el primero de ellos (Fig. 2) se detalla de manera integrada sus características geomorfológicas, litológicas y estructurales. En el segundo (Fig. 3) se enfatizan las variaciones laterales que afectan a la sucesión a lo largo de toda su exposición, para esto el afloramiento fue fotografiado en toda su extensión horizontal $(2,5 \mathrm{~km})$ e integrado digitalmente.

Los fósiles preservados en las unidades portadoras han sido descritos como clastos (abundancia relativa, articulación, color, brillo, textura, meteorización, etc.) con el objetivo de brindar una herramienta adicional en la taxonomía estratigráfica, como así también, ofrecer un potencial parámetro para la asignación estratigráfica de colecciones efectuadas previamente al inicio de este trabajo.

Las ubicación vertical de las inconformidades paleomagnéticas citadas por Heil et al. (2002), son ubicadas de acuerdo a las alturas indicadas en dicho trabajo y relativas al sector de muestreo señalado por uno de los autores (Zárate, com.per., 2006).

Los estudios geológicos aquí comunicados, tuvieron como base el informe de relevamiento geo-paleontológico efectuado por Pardiñas y Lezcano (1993, inédito) y el perfil estratigráfico levantado por Voglino (2001, inédito), ambos trabajos fueron gentilmente cedido por estos autores.

\section{Ubicación geográfica y caracterización geomorfológica}

Dentro de la llanura Chaco-pampeana, la localidad bajo estudio se encuentra en un sector periféri- 

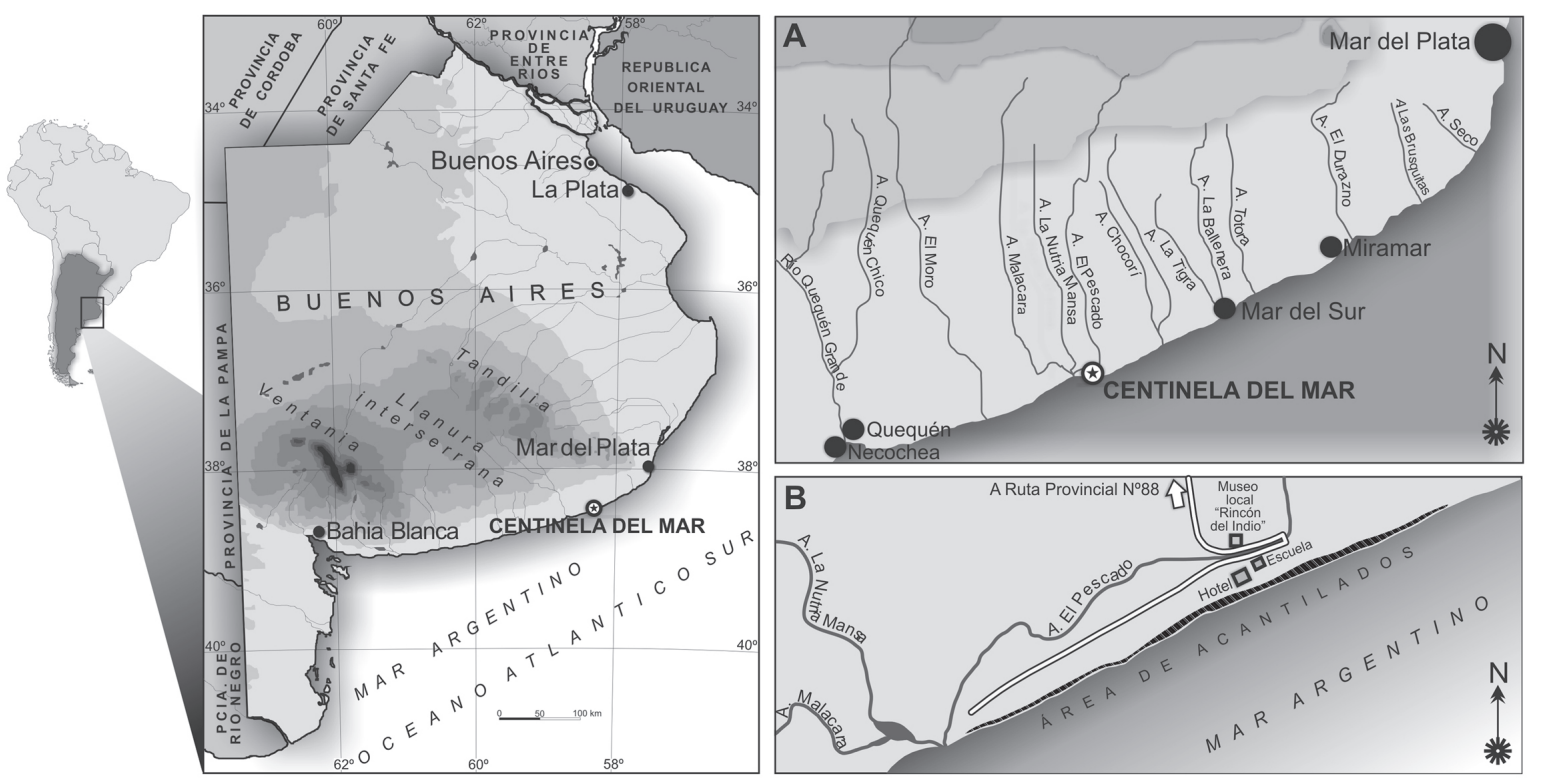

Fig. 1.-Ubicación geográfica del área de estudio. A) Detalle geográfico del sector litoral del área interserrana de la provincia de Buenos Aires al NE del Río Quequén Grande. B) Detalle geográfico de la localidad Centinela del Mar.



Fig. 2.-Perfil estratigráfico integrado de detalle para la sucesión sedimentaria expuesta en Centinela del Mar. 

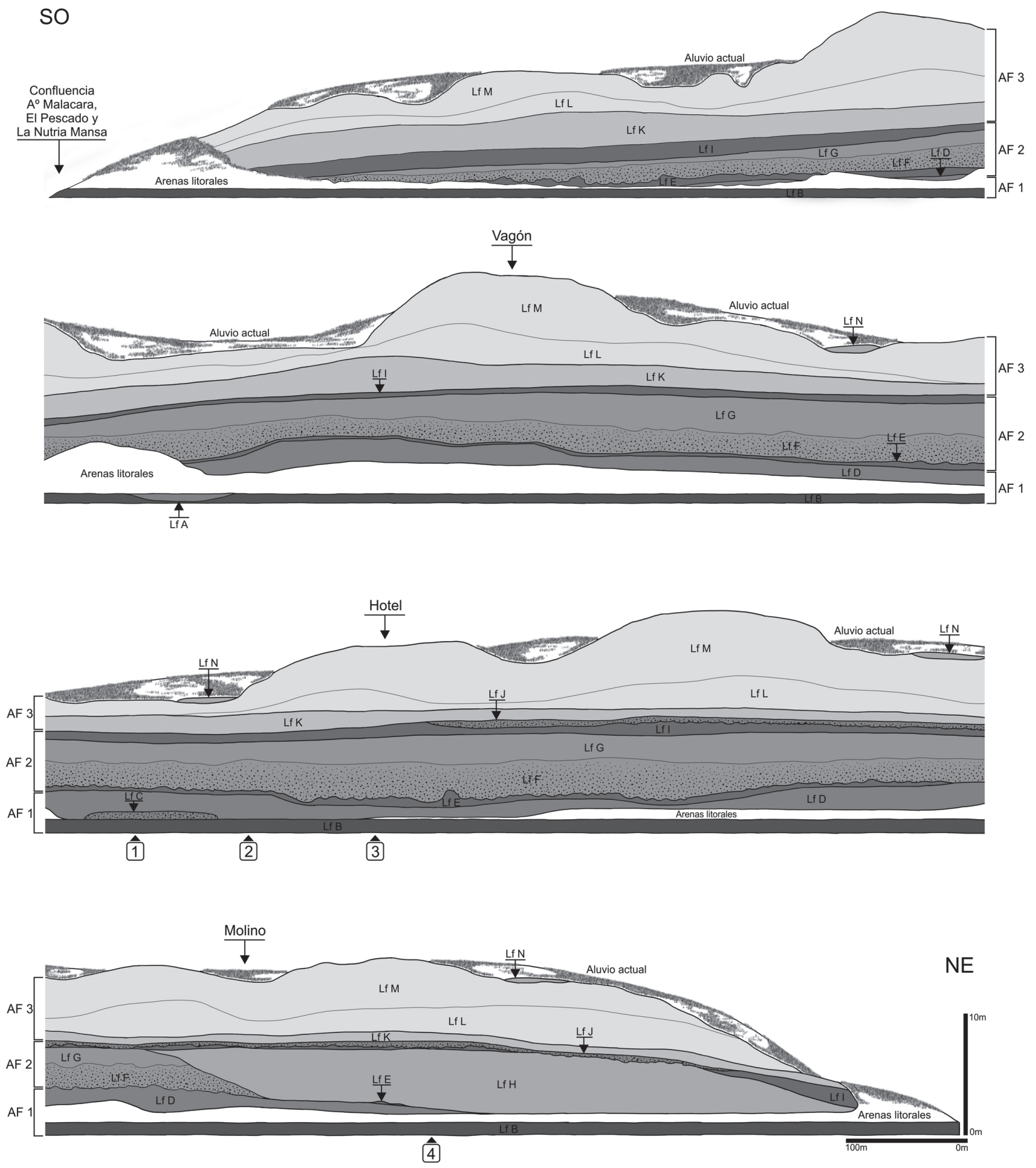

Fig. 3.-Perfil estratigráfico horizontal para la sucesión sedimentaria expuesta en Centinela del Mar. Los números en recuadro señalados en el margen inferior del esquema corresponden a los perfiles tipos (Figura 4). 
co hacia el centroeste del denominado «Positivo Bonaerense» o «Positivo de las Sierras Bonaerenses» (Yrigoyen, 1975). Dicha unidad morfoestructural, comprende las provincias geológicas de Tandilia y Ventania, como así también la intermedia «llanura interserrana bonaerense» (Rolleri, 1975, véase Fig. 1). Su límite nordeste se encuentra representado por la cuenca del Río Salado, mientras el sudoeste es demarcado por la cuenca del Río Colorado, en tanto, al noroeste esta limitado por el graben o semi graben de Vallimanca (Frenguelli, 1950; Zambrano, 1972; Yrigoyen, 1975). El mismo divide el drenaje hacia el Arroyo Vallimanca y hacia la costa atlántica con una pendiente de $0,40 \mathrm{~m} / \mathrm{km}$ y $1,20 \mathrm{~m} / \mathrm{km}$, respectivamente (Fidalgo et al., 1991).

La llanura interserrana, corresponde al área que Frenguelli (1950) definió como «Pampa Interserrana», terminología ampliamente empleada en la clasificación del paisaje bonaerense. Este sector del Positivo Bonaerense, comprende además las áreas pedimontanas de Ventania y Tandilia, conformando una planicie cuya cota máxima supera levemente los $200 \mathrm{~m}$ en la parte central entre ambos cordones serranos, descendiendo gradualmente hacia el océano Atlántico (Frenguelli, 1950; Zárate \& Rabassa, 2005).

El río Quequén Grande, de régimen permanente, es el curso de mayor importancia en la llanura interserrana, su valle se encontraría bajo control estructural (Zárate \& Rabassa, 2005) coincidiendo con el límite entre el sistema de Tandilia y Ventania (Fryklund et al., 1996).

Centinela del Mar se ubica hacia el nordeste del río Quequén Grande, este sector puede definirse como una planicie de pendientes bajas y regulares, surcada por arroyos de valles amplios y poco profundos con divisorias de aguas pobremente definidas en los tramos medio-distales (Fidalgo et al., 1975; Zárate \& Rabassa, 2005). Dichos valles se encuentran excavados en «sedimentos pampeanos» cubiertos por mantos eólicos más recientes de varios metros de espesor (Fidalgo et al., 1975; Zárate \& Rabassa, 2005).

En la localidad de Centinela del Mar (carta topográfica del IGM denominada «Centinela del Mar», Hoja $\left.\mathrm{N}^{\circ} 3957-7-2,1965\right)$ se levanta un acantilado litoral con una extensión de $2,85 \mathrm{~km}$ cuya altura fluctúa entre 5 y $15 \mathrm{~m}$. El mismo, es limitado al sudoeste por la confluencia de los arroyos El Pescado, La Nutria Mansa y Malacara (Fig. 1, B).

Según el criterio empleado por Marcomini y López (2005), la presencia de una amplia platafor- ma de abrasión, como así también, de cavernas en los acantilados de CdM, permitirían clasificarlo como un acantilado de tipo activo. No obstante, la ausencia de desplazamientos planares, el desarrollo de una amplia playa en su base y de vegetación arraigada en varios sectores, indica que su base se ve afectada principalmente durante las pleamares de sicigias o tormentas. Durante el verano la base del acantilado se encuentra menos expuesta ya que tiene un buen desarrollo de berma y rampas eólicas que impiden el lavado frecuente. De acuerdo a lo expuesto, inferimos que las condiciones variables del acantilado responden a las variaciones de la hidrodinámica regional (acantilado activo-inactivocon rampas eólicas). En este sentido, es importante señalar que el acantilado está afectado por las corrientes de deriva que siguen el contorno de la costa, en general con dirección norte (Codignotto \& Kokot, 2005).

El acantilado se inicia y finaliza abruptamente, las áreas lindantes constituyen desplayados conformados por campos de dunas transversales mayormente activos, cuyas dimensiones varían, pudiendo presentar los mismos una escasa a nula vegetación. Entre estos desplayados pueden observarse acantilados de escasa potencia y corta extensión, caracterizados como acantilados con rampas eólicas y/o mixtas (sensu Marcomini \& López, 2005).

Las prospecciones sobre los arroyos se limitaron a unos $1000 \mathrm{~m}$ aguas arriba de los arroyos El Pescado y Malacara. En su tramo distal, el primero de ellos quiebra $90^{\circ}$ la dirección de su cauce corriendo paralelamente al litoral marino, sus riberas no presentan barrancas de desarrollo significativo, cuando existen, siempre se encuentran conformadas por sedimentos arenosos actuales o subactuales. Por su parte el arroyo Malacara en su tramo distal corre primero encajonado entre barrancas para finalmente unir sus aguas con el arroyo La Nutria Mansa y El Pescado entre las grandes dunas litorales. En el sector donde corre encajonado, el Malacara presenta dos importantes escalones, el más distal de ellos posee una altura de unos $0,60 \mathrm{~m}$, su corte es neto y, a juzgar por la escasa cohesividad de los sedimentos de base, muy reciente. El escalón proximal se encuentra a unos $100 \mathrm{~m}$ aguas arriba del anterior, conforma saltos irregulares de hasta $0,80 \mathrm{~m}$ de altura que se encuentran labrados sobre mantos de tosca macizos y tabulares de difícil correlación con los que afectan los acantilados de CdM. Las barrancas del arroyo Malacara pueden llegar a tener una potencia de $4 \mathrm{~m}$, presentando al menos dos «terra- 
zas» (no representan verdaderas terrazas, véase Fidalgo et al., 1991) bien definidas. Sobre la de mayor edad y desarrollo vertical («terraza alta» sensu Frenguelli, 1950) se identificaron dos facies sedimentarias litológicamente similares entre sí, afines a los que se encuentran entre los desplayados lindantes y compuestas por loess arenoso en parte edafizado. Sobre esta primera «terraza» se desarrolla una segunda conformada por sedimentos eólicos actuales o subactuales (representa en realidad un manto eólico).

\section{Descripción de Facies}

En los acantilados de CdM fue reconocida (de base a techo) la siguiente sucesión de litofacies (véase Figs. 2, 3 y 4):

\section{Asociación de Facies 1 (AF 1)}

Litofacies A (Lf A): [Facies a, Zárate (1989); Fsm, Miall (2000)] Limos loessoides arcillosos, verde azulados, masivos, con nódulos calcáreos de muy pequeño tamaño $(<1 \mathrm{~cm})$ uniformemente diseminados (Fig. 2). Se trata de lentes de extensión restringida expuestos sobre la plataforma de abrasión, en algunos sectores es posible su verificación en la base de la barranca (Fig. 3). Su base no es observable, presentando contactos laterales netos, no erosivos. Los fósiles se encuentran altamente mineralizados (aspecto «vítreo»), los elementos de pequeño tamaño manifiestan coloración oscura (micro y mesovertebrados), en tanto, aquellos de mayor tamaño poseen una coloración castaño oscuro. Esta unidad representa lentes de pequeñas dimensiones producto de la depositación de carga en suspensión en cuerpos de agua pandos y tranquilos (Zárate, 1989).

Litofacies B (Lf B): [Facies Art, Zárate (1989); Sm, Miall (2000)] 0.50 a $1 \mathrm{~m}$ de limos loessoides arenosos, marrón oscuros, masivos, con nulas o escasas concreciones calcáreas (Fig. 2). Presenta una geometría homogéneamente tabular, su contacto basal es erosivo plano. La base es observable sobre la plataforma de abrasión, en tanto su techo generalmente se encuentra expuesto en la base del acantilado (Fig. 3). Los fósiles son abundantes, de coloración oscura y buena mineralización, principalmente representados por restos de microvertebrados, en algunos casos parcialmente articulados. Según Zárate (1989: 50) este tipo de facies suele encontrarse infrayaciendo a facies de «limolitas arenosas con estratificación irregular y paralela» (Lf D) e interrumpido lateralmente por contactos erosivos elaborados por paleocanales ( $\mathrm{Lf} \mathrm{C}$ ), en la sucesión de CdM se ratifican estas observaciones. Se trataría de episodios de desbordes de amplia extensión, la ausencia de estratificación y paleosuelos indicaría un proceso de sedimentación rápido (Zárate, 1989).

Litofacies C (Lf C): [Facies D, Zárate (1989); Gmm, Miall (2000)] 0.50 a $0.70 \mathrm{~m}$ de arenas limosas castaño-oscuras. Las abundantes concreciones calcáreas retrabajadas y su disposición caótica evidencia la naturaleza diamíctica del depósito (gravas masivas, matriz sostén, con pobre gradación). Su base no es visible, siendo sus contactos laterales erosivos. Presenta una extensión lateral restringida de $50 \mathrm{~m}$ (aflorante en la base de la sucesión a $300 \mathrm{~m}$ hacia el SO del hotel; Figs. 3; 4, perfil $1 ; 5$, B). Los escasos fósiles recuperados exhiben tonalidades claras con manchas dendríticas oscuras. Siguiendo a Zárate (1989 y bibliografía allí citada) este depósito es interpretado como facies de diamicto alojadas en un paleocauce y correspondientes a «flujos densos que colmataron por avulsión los canales de descarga» (1989: 49).

Litofacies D (Lf D): [Facies lmei, Zárate (1989); Sm-Sr, Miall (2000)] 1 a 2 m de limos loessoides arenosos rojizo-anaranjados, masivos, a veces de estructura pseudoescalonada y pseudoestratitificada, en ciertos sectores pueden manifestarse estructuras entrecruzadas pobremente definidas. Son características las intercalaciones regulares de toscas en enrejado coronando la unidad (Fig. 5, G), las cuales en algunos sectores pueden formar mantos de tosca en repisa. Su geometría general es mantiforme y tabular, presentando un contacto basal neto y plano. Hacia el SO se encuentra ampliamente representada sobre la plataforma de abrasión, observándose su mayor exposición vertical en el sector medio del afloramiento (al SO del hotel, Figs. 3 ; 4, perfiles 2 y 3). Los fósiles son extremadamente escasos y muy fragmentarios exhibiendo una coloración oscura. Son abundantes las crotovinas de gran tamaño (diámetro $>1 \mathrm{~m}$, posiblemente asignables a grandes tardígrados; véase Bargo et al., 2000; Vizcaíno et al., 2001; Fig. 5, E y G), claramente delimitadas por concreciones calcáreas de considerable espesor y rellenas por sedimentos laminados o masivos (ocasionalmente por cenizas volcánicas de color pardo). La unidad es interpretada como depositada bajo condiciones de alto régimen de flujo correspondientes a mantos de creciente (Zárate, 1989 y bibliografía allí citada).

\section{Asociación de Facies 2 (AF 2)}

Litofacies E (Lf E): [Facies a, Zárate (1989); Fl, Miall (2000)] 0.20 y $0.50 \mathrm{~m}$ de limos loessoides arcillosos, de coloración verdoso-azulada, muy plásticos. En estado seco se evidencia un «cuarteado» que se desgrana en estructuras prismáticas con caras recubiertas por películas de óxido de manganeso y hierro. Suelen observarse capas de arcillas finamente estratificadas. Es notable la presencia de concreciones calcáreas que varían su potencia y estructura (nodular, mamelonar y «en candelabro»), llegando a predominar sobre la fracción limosa como una capa de tosca de buena potencia, masiva y uniforme (Fig. 5, B). Hacia el techo estas concreciones suelen concentrarse formando un importante manto cuya extensión es relativamente constante en todo el afloramiento. El depósito presenta una geometría tabular cuyo contacto basal es neto y plano, siendo su techo conspicuamente seccionado por la Lf F (Figs. 3; 4, perfil 2; 5, A). Los fósiles son escasos y fragmentarios, exhibiendo una tonalidad oscura y un buen grado de mineralización. Según Zárate (1989) las facies de este tipo (estructura tabular y de gran extensión lateral) resultan complejas para su interpretación. Kraglievich (1952) consideró que se trataba de niveles de cenizas diagenizados, pero hasta el momento no existen estudios mineralógicos que lo avalen. Es plausible considerar a este depósito como facies de llanuras de inundación con el desarrollo de cuerpos lénticos.

Litofacies F (Lf F): [Facies cf. D, Zárate (1989); Gmm, Miall (2000)] 1 a 2 m de limos loessoides arenosos, castaños claros. 

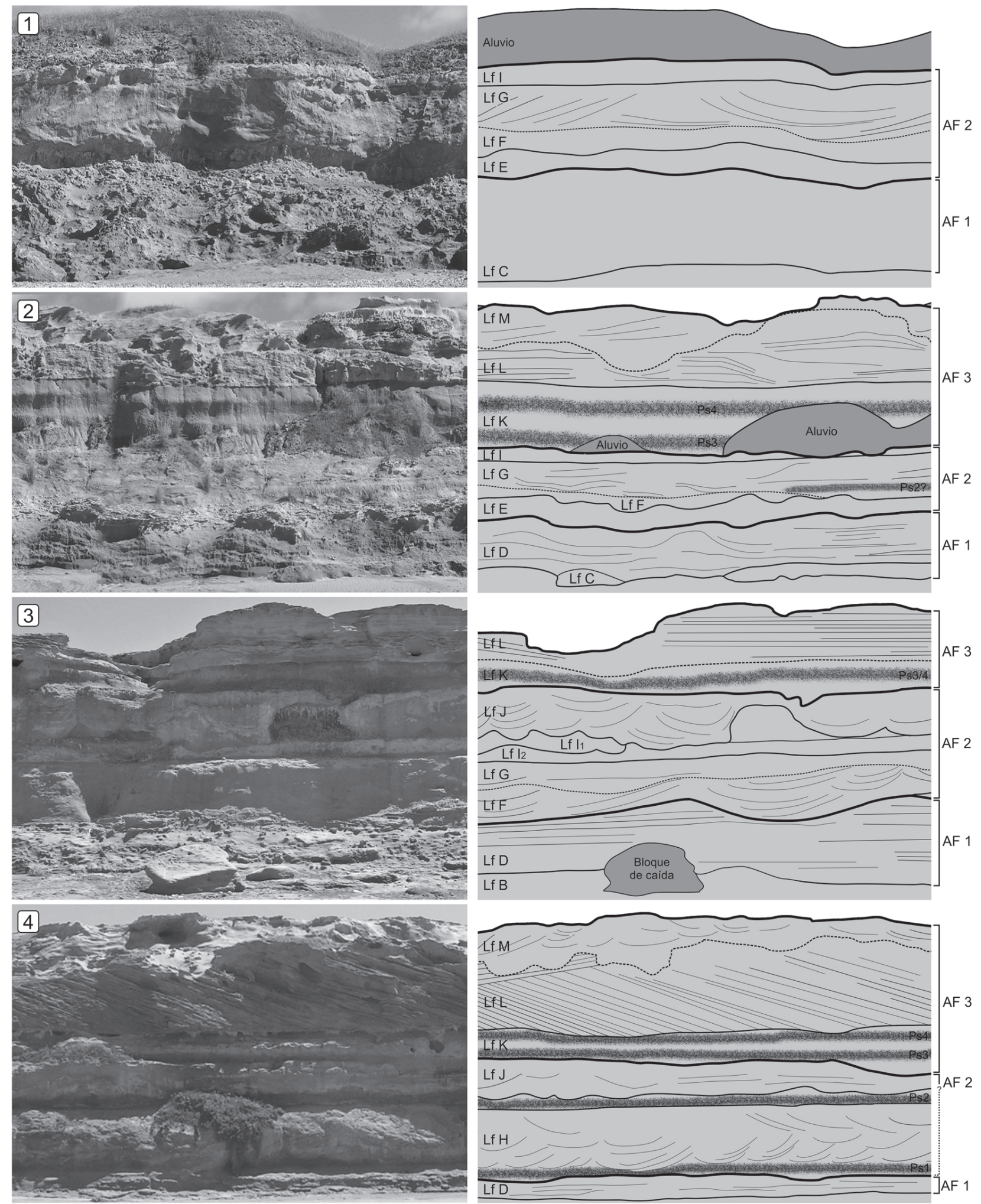

Fig. 4.-Detalle de los perfiles tipos de la sucesión sedimentaria expuesta en Centinela del Mar e indicados en la Figura 3. El grosor de los trazos señala la jerarquía de contactos. 

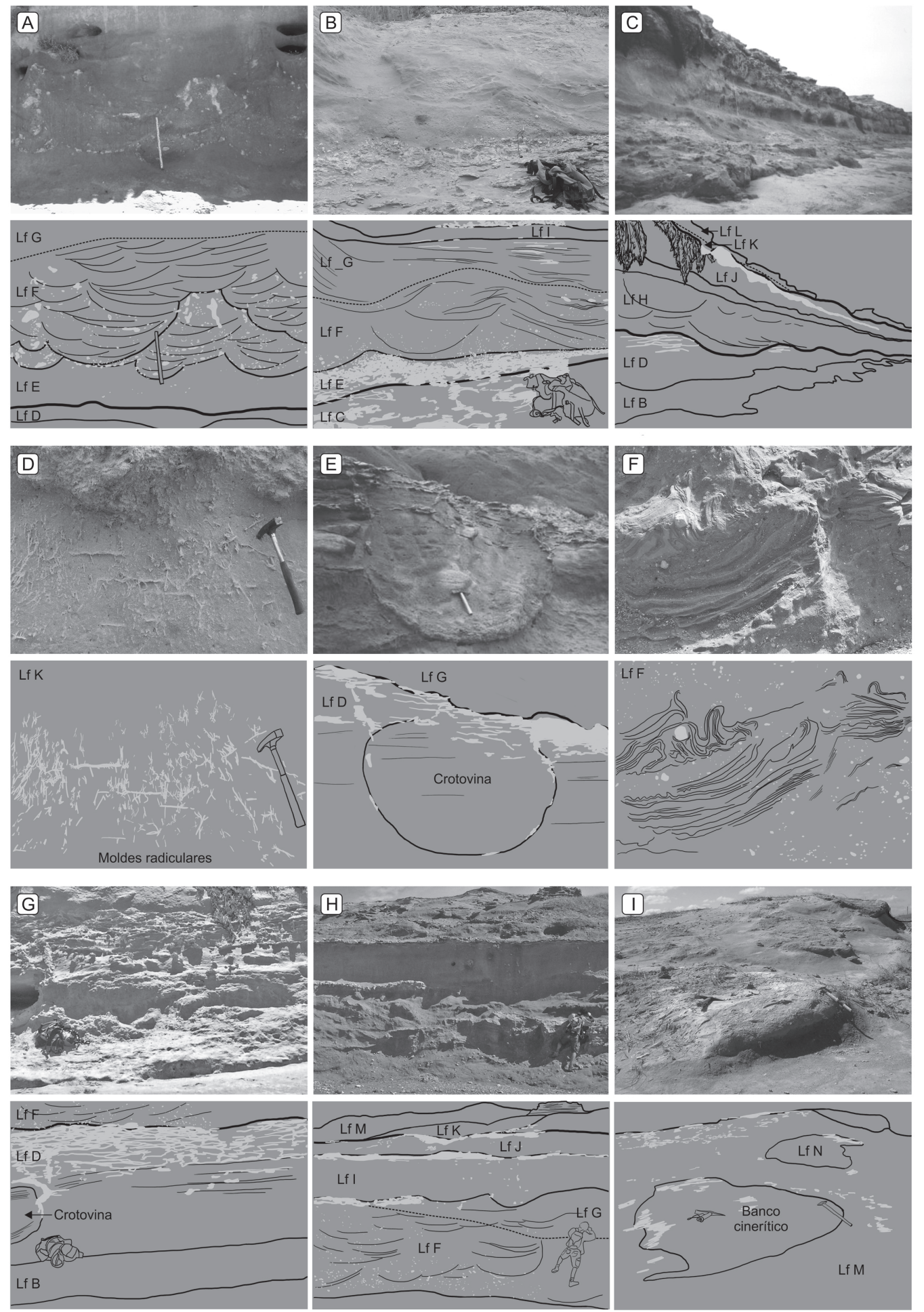

Fig. 5.-Detalles de las relaciones faciales y estructuras sedimentarias. A) AF 2, diamicto con mezcla de facies $F$ y $E$ (escala $1 \mathrm{~m}$ ); B) AF 2, contacto con Lf C (nótese la predominancia de concreciones dentro de la Lf E en este sector); C) Extensión horizontal de la Lf $\mathrm{H}$ y sus paleosuelos (Ps 1 y 2); D) moldes carbonáticos de raíces preservados en la Lf K; E) Crotovina adjudicable a grandes tardígrados excavada en la Lf D; F) Estructuras laminadas intraplegadas y nódulos calcáreos rodados conformando diamictos correspondientes a la Lf F; G) AF 1, Nótese la toscas en enrejado que coronan típicamente la Lf D; H) AF 2 y 3, detalle de relaciones faciales; I) Depósitos relictuales correspondientes a la Lf $\mathrm{N}$ con bancos cineríticos incluídos. El grosor de los trazos señala la jerarquía de contactos, las concreciones (toscas) son indicadas en gris. 
Son abundantes los clastos de concreciones calcáreas y limos arenosos grano-decrecientes con evidencias de retrabajo ácueo (gravas masivas, matriz sostén, con incipiente gradación normal; Figs. 2; 3; 5, A, B y H). Principalmente al SO de la sucesión se han identificado intraclastos angulosos de gran tamaño finamente laminados, como así también estructuras laminadas intraplegadas o convolutas (Fig. 5, F). El cuerpo presenta una geometría tabular muy extendida con una conspicua superficie de erosión irregular compuesta «integradas por superficies cóncavas hacia arriba, lateralmente coalescentes. Las áreas resultantes intermedias son fuertemente agudas y de flacos cóncavos» (Zárate, 1989: 48; Figs. 3; 5, A) confiriéndole un aspecto «aserrado». Los fósiles se encuentran bien preservados, con ejemplares articulados y no articulados. Como aquellos hallados en unidades inferiores, presentan una tonalidad oscura, no obstante, pueden diferenciarse de los últimos por presentar un brillo más opaco y alta porosidad. En su caracterización de este tipo de facies, Zárate (1989) señala que no existe selección textural en sentido vertical. Sin embargo, hemos advertido en esta unidad una gradación normal que señala una disminución en la energía del sistema hacia el techo hasta la total desaparición de los clastos carbonáticos en la matriz limo-arenosa (Figs. 5, A, B y H). La Lf F pasa gradualmente a la suprayacente Lf G, se fundamentó su división a los fines de un preciso control estratigráfico de la tafofauna colectada. Se trata de un diamicto depositado por flujos de detritos y/o barros que en algunos sectores manifiesta fuerte plasticidad. Según Zárate (1989), este tipo de facies es propia de áreas donde el aporte de material fino es abundante y la erosión rápida. La reducción de la cubierta vegetal debida al establecimiento de condiciones ambientales áridas podría provocar un incremento de este tipo en la tasa de sedimentación (Zárate, 1989 y bibliografía allí citada).

Litofacies $G$ (Lf G): [Facies cf. lmei?, Zárate (1989); Sm-Sr, Miall (2000)] 1 a $2 \mathrm{~m}$ de limos loessoides arenosos, castaños claros, en general con estructuras entrecruzadas (Figs. 5, A, B y H). Su geometría es mantiforme, siendo su contacto basal transicional (Figs. 3; 4, perfiles 1, 2 y 3). Presenta una potencia relativamente constante, ubicándose verticalmente en el sector medio del acantilado. Los fósiles se encuentran bien preservados, con ejemplares articulados y no articulados de tonalidad oscura, opacos y alta porosidad. Este nivel es portador de «escorias» o vidrios de impacto con evidencias de transporte que han sido datadas por técnicas radiométricas $\left({ }^{40} \mathrm{Ar} /{ }^{39} \mathrm{Ar}\right)$ en 230 $\pm 30 \mathrm{ka}$ (Schultz et al., 2004, véase Tabla 2).

Litofacies $H$ (Lf H): [Facies lmei?, Zárate (1989), Sm-Sr, Miall (2000)] Hasta $2.5 \mathrm{~m}$ de limos loessoides arenosos, rojizoanaranjados, con conspicuas estructuras entrecruzadas y numerosas subfacies de canales (Fig. 4, perfil 4). En la mayor parte del afloramiento, la unidad se encuentra ausente o representada de forma muy restringida, sin embargo, en los primeros $500 \mathrm{~m}$ de los acantilados (extremo NE) alcanza su máxima potencia (2,5 m) ocupando verticalmente el sector medio del perfil (ver Figs. 3; 5, C). Su exposición se inicia (en dirección NE-SO) como un conspicuo paquete sedimentario para finalmente acuñarse entre las unidades $\mathrm{G}$ e I. La unidad descansa sobre una superficie erosiva plana que afecta indistintamente a las infrayacentes unidades G, F, E y D. Los fósiles son sumamente escasos y de coloración oscura. La unidad es afectada por dos notables paleosuelos (Ps1 y Ps2; Figs. 2; 3; 4, perfil 4; 5, C) y son abundantes las crotovinas de pequeño tamaño asignables por sus dimensiones a roedores caviomorfos (véase Genise, 1989). Las evidencias edafogenéticas, indican un periodo de mayor estabilidad con tasas de sedimentación y erosión que fueron inferiores a la de formación de suelos, posiblemente en el interior un canal de régimen intermitente.

Litofacies I (Lf I): [Facies cf. a-lme, Zárate (1989); Fl, Miall (2000)] 0.5 y $1.5 \mathrm{~m}$ de limos loessoides arenosos, verdosos a verde-grisáceos, muy plásticos, con contenido de ceniza volcánica y pequeños rodados líticos $(3 \mathrm{~mm})$. En el sector medio de la exposición (alrededores del hotel), esta unidad se segrega en dos subfacies (Lf I1 y Lf I2), la superior es de coloración verdosa, en tanto la inferior es grisácea y algo más arenosa (Fig. 4, perfil 3). Su techo suele exhibir nódulos y/o toscas en candelabro (Fig. 4, perfil 3), en tanto su base generalmente presenta un conspicuo manto de tosca tabular. La unidad presenta geometría tabular y un contacto basal neto y plano sobre las subyacentes Lf H y G, siendo su techo perfectamente horizontal en todo el perfil (Fig. 3). Los fósiles se encuentran bien preservados, como ejemplares articulados y no articulados de tonalidad oscura y brillo vítreo. En el inicio de los acantilados (extremo $\mathrm{NE}$ ), se han recuperado algunos vidrios de impacto, tales estructuras suelen presentar un incremento de tamaño respecto a las reconocidas para otras unidades (Lf G y K). La génesis de esta litofacies es similar a la inferida para la Lf E y estaría vinculada a llanuras de inundación con la presencia de cuerpos lénticos (esto es congruente con la evidencia faunística disponible; e.g. Cenizo \& Ibáñez, 2006; Bogan et al., 2009).

Litofacies J (Lf J): [Facies cf. D, Zárate (1989); Gmm, Miall (2000)] Hasta 1.2 m de limos loessoides arenosos, castaño-grisáceos, con abundantes concreciones calcáreas retrabajadas (gravas masivas, matriz sostén, con pobre gradación) y fuertes estructuras entrecruzadas (Fig. 4, perfiles 3 y 4). Se trata de un depósito mantiforme cuyo contacto basal es erosivo y regular. La unidad ha sido identificada desde el extremo NE hasta el sector de hotel, encontrándose ausente hacia el SO de la exposición (Fig. 3). No se han recuperado fósiles de este depósito. Su génesis sería similar a la Lf F.

\section{Asociacion de Facies $3(A F 3)$}

Litofacies $K$ (Lf K): 1 a $1.5 \mathrm{~m}$ de limos loessoides arenosos, castaño-rojizos, masivos y friables, en general con pequeños restos de conchilla muy triturada, ocasionalmente con restos enteros de bivalvos marinos. El depósito presenta una geometría tabular muy extendida y manifiesta un contacto basal erosivo usualmente sobre la unidad I o J (Figs. 3; 4, perfiles 2, 3 y 4). Los fósiles exhiben una coloración parda amarillenta, normalmente recubiertos por carbonatos y afectados por una importante meteorización (gran fragilidad, colapsan fácilmente ante mínimas presiones). La unidad es afectada por dos eventos edafogenéticos (Ps3 yPs4) perfectamente discernibles al NE (Fig. 4, perfil 2 y 4), prevaleciendo hacia el SO solo uno de ellos (Fig. 4, perfil 3). Son notables los moldes carbonáticos de raíces (Fig. 5, D) e icnofósiles correspondientes a nidos de formícidos (véase Laza, 1995). Aquí se encuentra otra concentración de vidrios de impacto, dispuesta en dos capas. La mayor concentración proviene de la capa superior $(0.5-0.10 \mathrm{~m}$ de espesor) ubicada a $0.15 \mathrm{~m}$ del techo del paleosuelo $\mathrm{P} 4$ (horizonte A) y siempre asociadas a tierras cocidas (Schultz et al., 2004). Estos vidrios de impacto están mayormente intactos, reteniendo estructuras frágiles, por lo que se descarta la posibilidad de un transporte de alta energía de tipo fluvial (Schultz et al., 2004). La capa inferior, se halla a unos 0.20 a $0.50 \mathrm{~m}$ por 
debajo de la superior, estas «escorias» son más pequeñas $(<2$ $\mathrm{cm}$ ), se encuentran rotas y dispersas debido a la bioturbación posterior sobre la concentración definida en la capa superior. Los vidrios de la capa superior han sido datados por técnicas radiométricas $\left({ }^{40} \mathrm{Ar} /{ }^{39} \mathrm{Ar}\right)$ en $445 \pm 21 \mathrm{ka}$ (Schultz et al., 2004). El ambiente sedimentario al cual se pueda referir este depósito se encontraría representado por marismas, albuferas o estuarios (Isla et al., 2000; Schultz et al., 2004). No obstante las discrepancias sobre la génesis exacta de esta unidad, las evidencias sedimentarias y faunísticas indican ciertamente un ambiente de mezcla con el posterior desarrollo de suelos.

Litofacies L (Lf L): [Sp, Miall (2000)] 1 a $3 \mathrm{~m}$ de arenas medianas a gruesas, gris-amarillentas, bioclásticas, cementadas por carbonatos (hasta el $50 \%$; Isla et al., 2000). Los fósiles son extremadamente escasos y muy fragmentarios. El cuerpo sedimentario presenta geometría tabular (Fig. 3), siendo su contacto basal neto (a veces transicional), resultado de la colmatación de la litofacies estuarial inferior ( $\mathrm{Lf} \mathrm{K}$ ) por parte de paleodunas correspondientes a una barrera litoral. Dichas paleodunas preservan una estratificación entrecruzada de megaescala (Fig. 4, perfiles 3 y 4), con una inclinación tanto hacia el norte como hacia el este (Isla et al., 2000). Han sido hallados vidrios de impacto en la base de esta unidad (próximas al contacto con la Lf $\mathrm{K}$ ), las posición de las mismas sería producto de un retrabajamiento posterior (Schultz et al., 2004). La unidad descripta pasa transicionalmente a la unidad suprayacente ( $\mathrm{Lf} \mathrm{M})$, aumentando la composición loéssica y disminuyendo la granulometría de los bioclastos (se fundamentó su división a los fines de un preciso control estratigráfico de la tafofauna colectada). Aunque escasos, son observable lentes intraformacionales de mayor constitución loéssica (del tipo litológico observable en la Lf M), en tanto, lentes intraformacionales litológicamente similares a la Lf K pueden ser identificados al NE de la exposición.

Litofacies M (Lf M): [Sp, Miall (2000)] 1 a 2.5 m de sedimentos loessoides limo-arenosos (meteorización de la Lf L, con aporte de loess) castaño claro a amarillentos, con bioclastos más retrabajados que los de la unidad infrayacente. Geometría tabular y contacto basal transicional (Figs. 2 y 3 ). El ensamble fosilífero exhumado de esta unidad es el más numeroso y diverso de la localidad. La asociación incluye tanto megamamíferos como microvertebrados, en general desarticulados y con una buena preservación. Los restos muestran una coloración amarillo claro y habitualmente libres de concreciones, cuando existen siempre se manifiestan en forma de costras adosadas a los restos. Fueron registradas numerosas crotovinas, vacías (véase de los Reyes et al., 2006b) o rellenas de loess primario correspondiente a la unidad suprayacente ( $\mathrm{Lf} \mathrm{N})$. Las mismas representan icnofacies de diferentes tamaños, asignables a roedores y dasipódidos de gran tamaño (véase Imbellone \& Terruggi, 1988; Imbellone et al., 1990; Quintana, 1992; Bergqvist \& Maciel, 1994), algunas de las cuales atraviesan la Lf L llegando a observarse incluidas en la Lf K. Es remarcable la alta frecuencia de grietas de desecación rellenas por carbonatos. El conjunto de las Lf K, L y M conforman una asociación de facies (estuarial, dunas perilitorales y «cuerpos de agua» perilitorales, respectivamente), es decir, un sistema de progradación de ambientes vinculados a la ingresión marina Belgranense (Formación Pascua, sensu Isla et al., 2000).

Litofacies $N($ Lf N): Hasta $0.60 \mathrm{~m}$ de loess primario arenoso castaño-rojizo, muy friable. Se trata de un depósito completamente relictual que rellena oquedades y crotovinas transgresivas sobre la infrayacente Lf M (Figs 2; 3; 5, I). Su contacto basal es neto, correspondiente a superficies no depositacionales (sensu Zárate, 1989). Los fósiles son muy escasos, de una tonalidad amarilla clara. En el extremo NE de los acantilados pudo reconocerse un banco de cenizas blancas incluido en esta unidad, el cual probablemente corresponda al citado por Frenguelli (1928) en el interior de una paleocueva (Fig. 5, I). Se trata de depósitos eólicos primarios, con evidencias de retrabajamiento ácueo sinsedimentario (Zárate, 1989) y cuya génesis se encuentra relacionada al advenimiento de condiciones ambientales áridas (tormentas de polvo).

\section{Correlaciones locales}

Las exiguas exposiciones litorales inmediatamente lindantes que existen, tanto al NE de los acantilados, como al SO de la confluencia de los arroyos El Pescado, La Nutria Mansa y Malacara, presentan una potencia de pocos metros y se hallan generalmente cubiertos por rampas eólicas y/o aluviones actuales. No obstante, recientes prospecciones de un acotado sector de acantilados expuesto a unos 1000 $\mathrm{m}$ al SO de la confluencia de los citados arroyos, permitieron determinar la existencia, con ciertas modificaciones locales, de algunas facies relevadas en la secciones tipo de CdM. En el sector descripto la sucesión se inicia con la presencia de la Lf D, siendo la misma afectada por un fuerte contacto erosivo sobre la que se alojan conspicuos canales rellenos de diamictos correspondientes a las Lf F y E. Sobre estas últimas unidades se encuentra una potente representación de la Lf I, sin diferencias litológicas ni faunísticas evidentes con respecto a los acantilados de CdM. Es remarcable que en este sector las Lf I y E se encuentran suprayaciendo una a la otra, y dada la similitud litológica y cromática existente entre ambas, su diferenciación puede ser algo dificultosa. La sucesión local finaliza con un banco mantiforme de loess primario arenoso castaño claro (similar a la Lf N) con abundantes costras calcáreas y semejante al observado en los desplayados interiores (véase más abajo).

Por otra parte, prospecciones hacia el NE permitieron determinar, al menos de forma preliminar, que en todo el sistema de acantilados expuestos desde CdM hasta la localidad de Mar del Sur, existe esencialmente la misma sucesión estratigráfica descripta para los niveles basales y medios de CdM. En el marco de este trabajo, las facies vinculadas a la ingresión marina Belgranense (AF 3), hasta el momento sólo han sido identificadas en esta última localidad. Revistiendo excepción al respecto, dos pequeños lentes correspondientes a la Lf L identificados unos $1000 \mathrm{~m}$ al NE del arroyo Chocorí. 
Dichos bancos se encuentran depositados en paleodepresiones restringidas y ambos apoyan sobre una superficie de erosión que afecta la unidad eventualmente correspondiente a la Lf I de CdM. Asimismo, depósitos correlacionables con la AF 3 se encontrarían expuestos en el área de Monte Hermoso (Fidalgo el al., 1975) y Claromecó (Isla et al., 2001).

Alejándose del litoral marino, entre los médanos activos actuales, pueden observarse desplayados donde se exponen costras carbonáticas que al ser meteorizadas se manifiestan como conspicuos cúmulos de nódulos calcáreos. Sobre estas concreciones existen extensos depósitos mantiformes de loess primario arenoso castaño claro (de aspecto similar a la $\mathrm{Lf} \mathrm{N}$, aunque con un mayor contenido de arena). Incluidos en estos paleomedanos (diferentes en génesis y edad a las paleodunas correspondientes a las Lf $\mathrm{L}$ y $\mathrm{M}$ ) es común el hallazgo de ejemplares articulados y completos de megafauna.

Bond y Massoia (1981) describen una interesante tafocenosis hallada en depósitos fluviolacustres asignados al Pleistoceno Superior (Lujanense) y ubicados entre los desplayados a unos $2 \mathrm{~km}$ al NE de CdM. Recientes prospecciones han permitido reubicar dichos afloramientos, los cuales mostraron ser sedimentológicamente indiferenciables de aquellos correspondientes a la Lf I, integrando una asociación de facies idéntica a la observada en los acantilados de CdM.

\section{Discusión}

Como bien refiriera Zárate (2005) la nomenclatura y terminología constituyen el primer inconveniente al abordar el estudio de los depósitos neógenos de la región pampeana. Las diversas propuestas postuladas desde fines del siglo XIX evidencian las dificultades existentes para sistematizar las descripciones estratigráficas (Frenguelli, 1950). Actualmente los esquemas utilizados, principalmente litoestratigráficos, son numerosos y suelen utilizarse de forma simultánea. La falta de consenso en la comunidad científica conlleva dificultades tales como la incertidumbre respecto a la posición estratigráfica de restos fósiles, la extrapolación de inferencias paleoambientales a partir de secciones estratigráficas no representativas y correlaciones estratigráficas endebles (Zárate, 2005).

El caso de la sucesión de Centinela del Mar es un claro ejemplo de lo expresado anteriormente. Por esta razón a continuación y en orden cronológico, serán expuestas las diferentes interpretaciones efectuadas por los numerosos investigadores que se ocuparon de estos afloramientos (Tabla 1). En los casos en que sea posible, se señalan entre paréntesis las litofacies o asociación de facies correspondientes según el criterio adoptado en este trabajo.

La primera referencia sobre la geología de CdM fue comunicada por Torres y Ameghino (1913a, 1913b) manifestando que en el área comprendida entre las desembocaduras de los arroyos La Tigra y Malacara existe una "sucesión regular entre el ensenadense basal, interensenadense y ensenadense cuspidal» (1913a: 155). Agregan que el «bonaerense, $o$ piso superior de la serie pampeana» no se encuentra representado en al área, argumentando la abundancia de ejemplares de Glyptodon muñizi (elemento faunístico característico del Piso-Edad Ensenadense, véase Ameghino 1889; Cione \& Tonni, 2005; Soibelzon et al., 2006). No obstante, las características citadas por Torres y Ameghino (1913a; 1913b) no son suficientes para diagnosticar la especie (véase diagnosis enmendada, Soibelzon et al., 2006). Por otra parte, no se ha podido constatar la existencia en las colecciones oficiales de ejemplares que provengan del área al sudoeste de Mar del Plata y presenten las características diagnósticas de $G$. muñizi (Soibelzon, com.per., 2006). Los errores interpretativos iniciales respecto a la edad de las unidades sedimentarías de CdM (véase Daino, 1979 y bibliografía allí citada) llevaron a considerar los restos arqueológicos hallados sobre la ribera sur del arroyo El Pescado («túmulo del Malacara», Torres \& Ameghino, 1913a, 1913b) como de antigüedad ensenadense (Plioceno Superior sensu Ameghino, 1889) cuando en realidad representan facies eólicas relativamente recientes. Finalmente, Torres y Ameghino (1913a, 1913b) concluyen que los depósitos «postpampeanos» solo se observan en las desembocaduras de los arroyos, ya sea como facies marinas o fluvio-lacustres, omitiendo referencia alguna sobre las facies eólicas «postpampeanas».

Roth (1920: 286) indica para la localidad la presencia de «una arenisca compuesta de arena y fragmentos de conchillas... que presentan la característica estratificación eólica de los médanos» (Lf L y M) depositada sobre «loess del horizonte mesopampeano» (correspondiente al Ensenadense sensu lato de Ameghino, 1889; Lf A-K). Según dicho autor, estos «médanos» presentan en su parte superior «el aspecto de loess muy arenoso» (Lf N).

Frenguelli (1921) reconoce en la base de la exposición de CdM sus terrenos «prebelgranenses» 


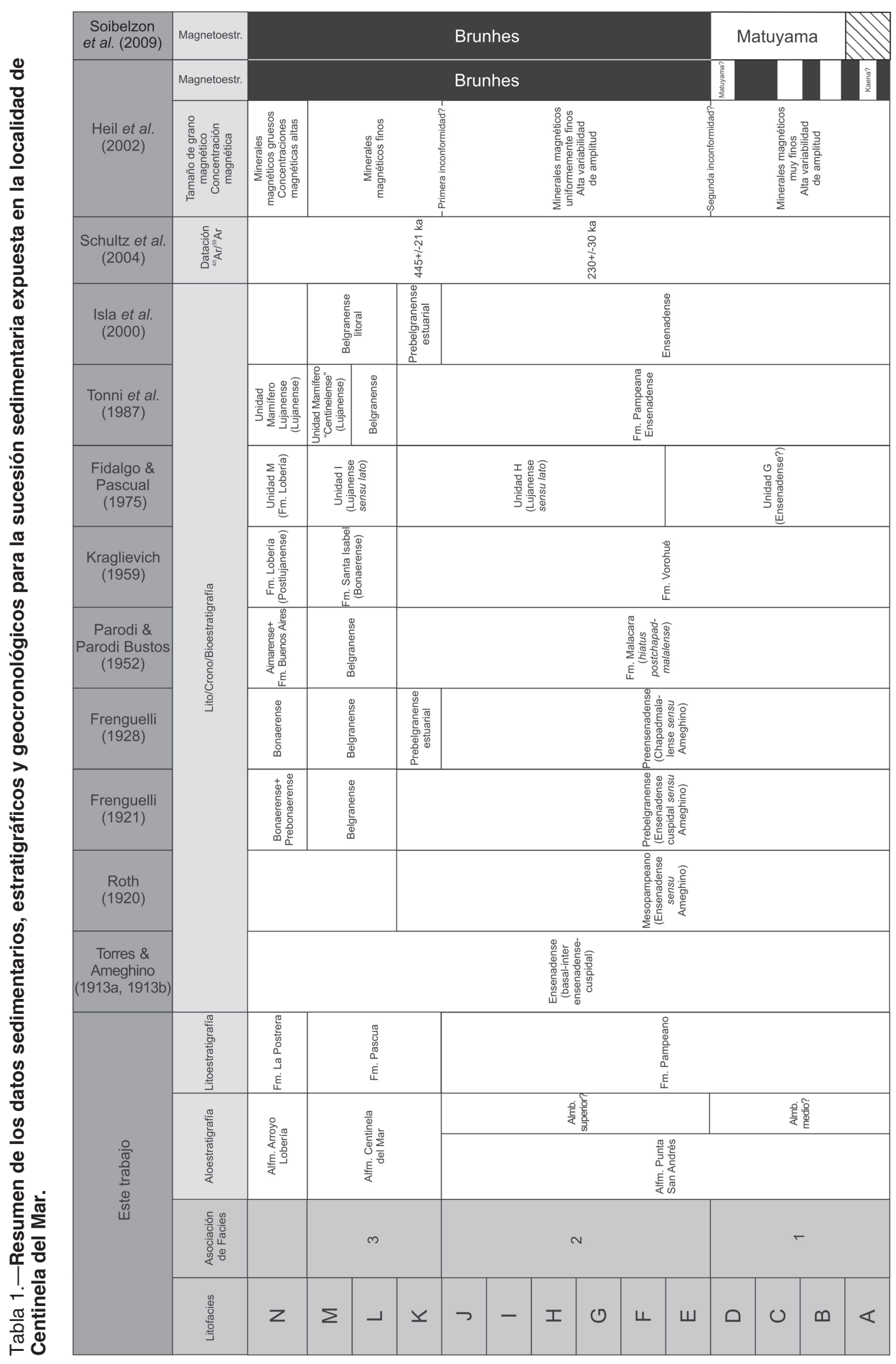

Estudios Geológicos, 67(1), 21-39, enero-junio 2011. ISSN: 0367-0449. doi:10.3989/egeol.40283.125 
(correspondientes al «Ensenadense cuspidal»sensu Ameghino, 1889; Lf A-K) sobre los cuales, descansan los «depósitos eolomarinos» pertenecientes al «Belgranense típico» (Lf L y M). Según este autor, estas arenas bioclásticas se hallan cubiertas por un banco de loess «bonaerense» (Lf N). Finalmente, señala que «en algunos puntos entre los horizontes belgranense y bonaerense se intercala pequeñas lentes de arcilla verdosa, que atribuimos al prebonaerense (lujanense)»(1921: 435; no identificado en este trabajo). Posteriormente, Frenguelli (1928: 77) redefine el esquema previo (1921) indicando que «los limos basales con escorias atribuidos por mi al Prebelgranense» en realidad pertenecen al «Preensenadense» (adjudicándole una «edad chapadmalalense» sensu Ameghino, 1889; AF 1 y 2), restringiendo el primer termino al horizonte ubicado entre el «Preensenadense» y el «Belgranense» (Lf K). Por último, en esta revisión Frenguelli refiere que la exposición culmina con un banco de loess «Bonaerense» (Lf $\mathrm{N})$, omitiendo referencia alguna sobre su «prebonaerense» señalado previamente (1921).

La base del perfil fue descrita como «Formación» Malacara por Parodi y Parodi Bustos (1952) y refierida al «hiatus postchapadmalalense» (intermedio entre los "horizontes chapadmalalense y ensenadense» sensu Ameghino, 1889; Lf A-K), el cual se correspondería con el «Uquiense» (véase Pascual et al., 1965; invalidado por Cione y Tonni, 1995). Según lo expresado por estos autores (1952: 142), sobre la unidad descripta descansan dunas consolidadas de "edad Belgranense» (Lf L y M), y estas últimas se hallan cubiertas por restos de un depósito pulverulento «equivalente a la formación Buenos Aires» (Lf N). Finalmente, Parodi y Parodi Bustos indican que en algunos sectores periféricos al acantilado puede observarse terrenos negruzcos asignados al «Aimarense». Esta última referencia no ha sido identificada en el sector de acantilados de CdM, sin embargo, depósitos de estas características pueden ser advertidos en las barrancas de los arroyos lindantes.

Posteriormente, Kraglievich (1959) declara nula la «Formación» Malacara, argumentando que contiene dos entidades estratigráficas diferentes, los términos a y b (Lf A-E) de su perfil corresponderían a $\mathrm{su}$ «Formación» Vorohué, en tanto el complejo $\mathrm{c}_{1-3}$ (Lf F-K) se correlacionarían con su «Formación» Miramar. La «Formación» Vorohué y la suprayacente Formación. San Andrés fueron definidas originalmente para el área Mar del Plata-Miramar por Kraglievich (1952) como entidades estratigráficas dis- cretas (aunque no formales; para una descripción formal de esta última unidad véase Teruggi et al., 1974). Sin embargo, en el trabajo citado inicialmente, Kraglievich (1959: 6) considera a ambas unidades como única entidad estratigráfica reunidas bajo el nombre de «Formación» Vorohué correspondiendo al "Ensenadense basal-Preensenadense hasta el Ensenandense cuspidal» (sensu Ameghino, 1889). En cuanto a los depósitos superiores (término d de Kraglievich, 1959) considerados como "eolomarinos» o «Piso Belgranense» (Lf L y M) el autor los asigna a su «Formación» Santa Isabel y los correlaciona con los depósitos litorales de la zona de Mar del Plata vinculados a una ingresión marina interglacial y asignados por él a la «fase Lujanense de la Edad Bonaeriana». Sobre esta última unidad, Kraglievich identifica los depósitos loésicos de su «Formación» Lobería correspondiente a una edad «Postlujanense» (Lf $\mathrm{N})$.

En su notable síntesis sobre la geología superficial de la llanura bonaerense, Fidalgo et al. (1975) discuten y reinterpretan los perfiles estratigráficos de CdM efectuados por Parodi y Parodi Bustos (1952) y Kraglievich (1959), reenumerando las unidades establecidas por el segundo autor. En este esquema indican que los términos $\mathrm{G}$ y $\mathrm{H}$ de su perfil corresponden a las unidades a, b y c de Kraglievich (1959) y señalan el hallazgo de mamíferos de «Edad ensenadense» en la playa, conjeturando que esta unidad podría estar representada en los niveles de restinga (AF 1). Para los niveles «medios y superiores» (AF 2 y 3 ) refieren el hallazgo de «mamíferos taxonómicamente semejantes a aquellos de la Formación Arroyo Seco de las barrancas de Chapadmalal, que por su grado evolutivo hemos referido a la Edad Lujanense» (1975: 122; Lujanense sensu lato = Lujanense + Bonaerense sensu Cione y Tonni, 2005). Estos autores reafirman la presencia en los niveles superiores de su unidad $\mathrm{H}$ (término $\mathrm{c}_{3}$ de Kraglievich, 1959; Lf K) de rodados alóctonos (sugerido también por Kraglievich, 1959) y que anuncian la instauración de un ambiente de playa, como el que indican los superpuestos niveles del «Belgranense» (Lf L y M). Durante los trabajos de campo llevados a cabo en el marco de esta contribución no se ha podido constatar la presencia de dichos rodados. El término I de Fidalgo et al. (1975; Lf L y M) es descripto como: "areniscas entrecruzadas, compactas, con mucho detrito conchil» indicando que «se trata de depósitos de playa marina». Según dichos autores (1975: 122) estos depósitos son correlacionables con aquellos de similares caracte- 
rísticas que «esporádicamente aparecen en algunos trechos de las barrancas marinas que discontinuamente siguen hasta Monte Hermoso...». Agregan la presencia en esta unidad de mamíferos considerados como característicos de la «Edad Lujanense» (Lujanense sensu lato) y consideran que posiblemente se trate de litofacies diacrónicas de una misma unidad cronoestratigráfica (Lujanense sensu lato). Esta idea sería más tarde argumentada con mayores evidencias geocronológicas y bioestratigráficas para otro sector del área interserrana (i.e. Río Quequén Grande, véase Pardiñas et al., 1996; Cione \& Tonni, 1999). Finalmente, Fidalgo et al. (1975) correlacionan su unidad M (Lf N) con la «Formación» Lobería «del área de Chapadmalal».

El primer aporte bioestratigráfico significativo para la localidad corresponde a Tonni et al. (1987). Estos autores indican que los niveles basales (Lf A$\mathrm{K})$ pertenecen en sentido amplio a la «Formación Pampeana», seguido por los depósitos «eolomarinos» o «piso belgranenese» de Ameghino (1889) (Lf L). Sobre la unidad precedente, identifican un nivel litológicamente similar a la Formación La Postrera (sensu Fidalgo et al., 1973a), al que dividen en dos subniveles. El subnivel inferior (Lf M) es el portador de la asociación mamaliana sobre la que establecen la Fauna Local «Centinela del Mar», provisoriamente referida a una nueva Unidad Mamífero denominada «Centinelense», asignable al Pleistoceno Superior y anterior a la Unidad Mamífero Lujanense (para una definición de estas unidades bioestratigráficas véase Tonni et al., 1985, 1987; para una crítica a las mismas véase Cione \& Tonni, 1995). El subnivel superior (Lf N) es referido a la Unidad Mamífero Lujanense por la presencia de Equus (Amerhippus) cf. curvidens (auct. E. [Amerhippus] cf. neogeus), integrante característico de dicha unidad. Ambas Unidades Mamífero, «Centinelense» y Lujanense son incluidas dentro de la Edad Mamífero Lujanense (auct. Piso-Edad Lujanense sensu Cione \& Tonni, 2005). Cabe destacar, al menos como antecedente, que E.P. Tonni (apreciación personal en Cione \& Tonni, 1995) manifiesta la presencia de fauna ensenadense en los niveles inferiores de CdM.

En su revisión sobre la transgresión marina Belgranense, Isla et al. (2000) reconocen para CdM facies eólicas de la Formación Pascua, representadas por una barrera medanosa litoral vinculada a dicha transgresión (Lf L y M). Por debajo de estas dunas consolidadas identifican ambientes de mezcla asignables a marismas (Lf K).
Las controversias sobre la edad de los depósitos marinos de la provincia de Buenos Aires son sustanciales, principalmente respecto a sus orígenes, número, edad y relación con otros depósitos (Aguirre \& Whatley, 1995; Isla et al., 1996). El «piso belgranense» fue propuesto originalmente por Ameghino (1889) para denominar los bancos de marinos aflorantes en las Barrancas de Belgrano (ciudad de Buenos Aires) y asignados por él al Pleistoceno Medio. En tanto, Roth (1920) y Frenguelli (1928) los refieren al Pleistoceno Superior. Posteriormente, el «piso belgranense» de Ameghino fue redefinido como Formación Pascua (Fidalgo et al., 1973b) y Formación Canal 5 (Violante \& Parker, 1992). Las dataciones por U/Th sobre Tegula patagonica obtenidas de los médanos consolidados de Claromecó arrojaron una edad de 93,5 $\pm 3,5 \mathrm{ka}$ AP (Isla et al., 2000). Conforme con dichos fechados, Isla et al. (2000) correlacionan los sedimentos belgranenses (incluidas las facies estuarial, dunas perilitorales y «cuerpos de agua» perilitorales de $\mathrm{CdM}=\mathrm{AF} 3$ ) con el interglacial Sangamoniano o Tirreniano de circa 120 ka AP (estadío isotópico 5e).

Heil et al. (2002) realizan un estudio de paleomagnetismo y magnetismo mineral sobre el perfil expuesto, detectando dos posibles inconformidades magnéticas. Los dos tercios superiores (AF 2 y 3?) mostraron una polaridad normal correspondiente a la época Brunhes, mientras que el tercio inferior por debajo de la segunda inconformidad (AF 1?) muestra cuatro campos reversos, uno de ellos es tentativamente asignado por dichos autores al Evento Kaena (3,04-3,11 Ma). De acuerdo a los cambios en la concentración magnética y el tamaño de grano magnético, Heil et al. (2002) identifican cuatro regímenes depositacionales en la sucesión (véase Tabla 1), los cuales (de acuerdo a las alturas de muestreo reportadas) muy posiblemente correspondan a las cuatro principales unidades sedimentarias reconocidas en este trabajo (i.e. $\mathrm{AF} 1,2,3$ y Lf $\mathrm{N}$ ).

Estudios recientes sobre magnetoestratigrafía (Soibelzon et al., 2009) efectuados en CdM tomando como referencia el perfil estratigráfico aquí comunicado (Fig. 2, Tabla 1) indican que las unidades de la sección media y superior poseen polaridad normal (AF 2 y 3), en tanto fue detectada la presencia de un evento de polaridad reversa en las Lf B-D, mientras que la Lf A resultó problemática (polaridad oblicua reversa). Siguiendo este criterio, el límite Brunhes-Matuyama se encontraría en la base de la sucesión (entre las Lf E y D) y la AF 1 tendría una antigüedad mayor a los 0,78 Ma. Estos datos 
son congruentes, al menos en parte (sector medio y superior de la sucesión = Cron Brunhes), con los datos proporcionados por Heil et al. (2002), existiendo discrepancias sobre la identidad del evento reverso detectado en la base de la exposición ya que estos últimos autores lo asignan al Evento Kaena del Cron Gauss (Piso/Edad Barrancalobense, Plioceno Medio superior, Cione \& Tonni, 2005).

La presencia de «escorias» en los acantilados de Centinela del Mar, fue vinculada por Schultz et al. (2004) a dos impactos meteoríticos en la región. De acuerdo a dichos autores, los vidrios de impacto provienen de dos unidades, la concentración inferior ( $\mathrm{Lf} \mathrm{G}$ ) fue datada por técnicas radiométricas de alta resolución $\left({ }^{40} \mathrm{Ar} /{ }^{39} \mathrm{Ar}\right)$ en $230 \pm 40 \mathrm{ka} \mathrm{AP}$, en tanto la superior ( $\mathrm{Lf} \mathrm{K}$ ) arrojo una edad de $445 \pm 21$ ka AP. La inconsistencia entre las edades radiométricas y la posición estratigráfica (los vidrios superiores son más antiguos que los inferiores) fue explicada por Schultz et al. (2004) argumentando que los vidrios de la unidad superior fueron redepositados en lagunas costeras durante la última transgresión marina de circa 125 ka AP. Estos autores no realizan aportes estratigráficos significativos, no obstante, señalan que la acumulación superior de escorias «occur within a relatively narrow horizon just below a marine transgression expressed by a series of coastal paleo-dunes and systematic changes in the underlying sediments» (2004: 221).

Si bien Schultz et al. (2004) refieren la presencia de solo dos unidades portadoras de vidrios de impacto $(\mathrm{G}$ y $\mathrm{K})$, nosotros también los hemos detectado en la Lf I (intercalada entre las Lf G y K). Aunque menos abundantes, en algunos casos estas «escorias» presentan evidencia de un menor transporte y mayor tamaño respecto a las halladas en las unidades superiores e inferiores. La determinación de su edad absoluta podría brindar nuevas herramientas geocronológicas como así también, evidencias auxiliares en relación a la incongruencia estratigráfica dada por las dataciones efectuadas por Schultz et al. (2004). La existencia de «tierras cocidas» en torno a las acumulaciones de vidrios de impacto provenientes de la Lf $\mathrm{K}$ arroja ciertas dudas respecto a los argumentos sostenidos por Schultz et al. (2004) para explicar la citada incongruencia. De acuerdo a la interpretación sugerida por Schultz et al. (2004), los sedimentos portadores de los vidrios de impacto originales se encuentran ahora perdidos debido a una inconformidad erosiva vinculada a las subsecuentes transgresiones marinas posteriores al impacto (410 ka y $340 \mathrm{ka}$ AP) y no preservadas en el registro sedimentario. $\mathrm{Si}$ bien esta hipótesis ad hoc es plausible, debemos agregar que aunque los vidrios de impacto no se hallan in situ, en la mayoría de los casos se encuentran acompañados de pequeños pero abundantes fragmentos de «tierras cocidas» y dada la densidad diferencial entre ambos tipos de estructuras, el transporte de las mismas debe haber sido mínimo, hecho que también es señalado por Schultz et al. (2004).

Los depósitos eólicos «postpampeanos» (Lf N, sedimentos que constituyen las barrancas del arroyo Malacara y el sustrato de los desplayados lindantes al área de acantilados) son comunes en toda la provincia de Buenos Aires, hallándolos tanto sobre los pedimentos de Tandilia y Ventania como en las llanuras circundantes. Se trata de sedimentos inconsolidados, integrados por limos loessoides arenosos (loess primario sensu Frenguelli, 1955) y arenas limosas, que en general muestran un color uniforme, aspecto homogéneo y ausencia de todo tipo de estratificación (Frenguelli, 1955; Fidalgo et al., 1975, 1991). Acumulados sobre «sedimentos pampeanos», pueden verificarse como mantos de hasta varios metros de espesor en divisorias y planicies de inundación (Fidalgo et al., 1975, 1991; Zárate \& Rabassa, 2005). El loess volcaniclástico que conforma esta unidad, o conjunto de unidades, habría sido transportado principalmente desde el norte de Patagonia por vientos del sud-sudoeste durante la deglaciación posterior al Último Máximo Glacial (UMG; Zárate \& Blasi, 1993; Sayago, 1995; Sayago, et al., 2001; Smith et al., 2003).

Posiblemente el estudio geológico de mayor detalle y amplitud geográfica efectuado para las sucesiones sedimentarias de la costa atlántica bonaerense corresponda al de Zárate (1989). Si bien, dicho trabajo se restringió al sector de acantilados comprendido entre Playa San Carlos y el Arroyo Chapadmalal (unos $50 \mathrm{~km}$ al NE de la localidad bajo estudio), el esquema aloestratigráfico propuesto puede ser considerado de carácter regional brindando un excelente marco teórico y metodológico a los fines de consensuar un esquema estratigráfico para el área interserrana. Dos de las cinco aloformaciónes postuladas por Zárate (1989) pueden reconocerse en CdM (véase Tabla 1): Aloformación Punta San Andrés y Aloformación Arroyo Lobería. Las características citadas por Zárate (1989) en su descripción de la Aloformación Punta San Andrés son coincidentes con las observadas en el conjunto de las AF 1 y 2 de CdM (e.g. amplio predominio de agentes de transporte ácueo; gran abundancia y diversidad de toscas, principalmente mantos de tosca), y perfectamente 
discernible de las aloformaciones inferiores y superiores (e.g. predominio de facies de limos masivos friables, toscas mamelonares de gran desarrollo y bancos de tosca masiva). Zárate (1989) basándose en los estudios magnetoestrátigraficos de Orgeira (1988) y Roucco (1989) indica que el miembro superior de dicha aloformación es de polaridad normal, en tanto, el techo del miembro medio sería de polaridad inversa. Siguiendo este criterio magnetoestrátigrafico y los estudios antes citados de Heil et al. (2002) y Soibelzon et al. (2009), es posible que las AF 1 y 2 correspondan, respectivamente, a los alomiembros medio y superior de la Aloformacion Punta San Andrés. La Lf N que culmina la sucesión de $\mathrm{CdM}$, corresponde indudablemente a la sección superior de Aloformación Arroyo Lobería descrita por Zárate (1989). En tanto, la AF 3 (facies de la Formación Pascua) que se intercala entre las dos unidades aloestratigráficas antes citadas, no fue identificada en el área de estudio de Zárate (1989), por lo que es nominada aquí como Aloformación Centinela del Mar (siendo CdM su sección tipo). Esta unidad se encuentra definida basalmente por la superficie erosiva que la separa de la Lf J e I, siendo su límite superior determinado por el contacto neto sobre la que se depositó la Lf N (véase Descripción de Facies, Figs. 2; 3; 4, perfiles 1, 2 y 3).

\section{Conclusiones}

En el presente trabajo se han identificado 14 litofacies $(\mathrm{A}-\mathrm{N})$ para la sucesión sedimentaria que conforman los acantilados litorales expuestos en la localidad de CdM. Dichas unidades integran cuatro unidades sedimentarias principales: AF 1 (Lf A-D), AF 2 (Lf E-J), AF 3 (Lf K-M) y Lf N.

De acuerdo al análisis efectuado sobre los esquemas propuestos previamente, el perfil estratigráfico efectuado por Kraglievich (1959) fue el que presentó mayor similitud en la identificación de unidades con el aquí descripto.

Sedimentológicamente, la sucesión muestra una preponderancia de facies loessoides limo-arenosas correspondientes a camadas aluvionales de diferente fluidez, retrabajo y transporte ácueo, representadas por bancos masivos y homogéneos (episodios rápidos de desborde de amplia extensión), diamictos (flujos densos) y estructuras entrecruzadas (mantos de creciente, inundaciones repentinas y violentas). Los diamictos pueden encontrarse encauzados (Lf C) o representados por horizontes de gran extensión
(Lf $\mathrm{F}$ y $\mathrm{J}$ ), estos últimos podrían considerarse eventualmente, como eventos regionales de flujos densos de barro (Zárate, 1989). De acuerdo a interpretaciones previas estos diamictos podrían estar vinculados a condiciones climáticas áridas a semiáridas (Tonni y Fidalgo, 1982; Zárate, 1989). Las facies de limos loessoides arcillosos se encuentran intercaladas entre las facies limo arenosas aluvionales, algunas representan cuerpos de agua lenticulares de pequeñas dimensiones (Lf A), otros (Lf E e I) de gran desarrollo lateral, representan horizontes guías regionales y que de acuerdo a sus características sedimentarias, tafonómicas y faunísticas pueden ser vinculadas a llanuras de inundación con desarrollo de cuerpos lacustres y/o palustres de relativa extensión. Facies de arenas finas a gruesas (AF 3 ) de origen marino son interpretadas como un sistema de progradación de ambientes marinos litorales, comenzando con el advenimiento de depósitos de mezcla (Lf K), seguido por el establecimiento de dunas perilitorales ( $\mathrm{Lf}$ L) y concluyendo con la presencia de «cuerpos de agua» perilitorales. Facies de loess primario culminan la exposición, constituyendo un depósito eólico mantiforme actualmente en aparente retroceso y correspondiente al advenimiento de condiciones climáticas más secas y frías que las actuales (UGM, circa 20-19 ka AP).

En un sentido litoestratigráfico estricto, las AF 12 y AF 3 son referidas a la Formación Pampeano y facies progradantes de la Formación Pascua, respectivamente. En tanto, la Lf $\mathrm{N}$ es aquí asignada a la Formación La Postrera.

Siguiendo el esquema de aloestratigráfico propuesto por Zárate (1989) correlacionamos aquí, tentativamente, la AF 1 y 2 con la Aloformación Punta San Andrés y la Lf N con la Aloformación Arroyo Lobería. Para la AF 3 (intermedia entre las dos aloformaciones precedentes) se propone una nueva unidad denominada Aloformación Centinela del Mar.

Las aproximaciones bioestratigráficas que deriven de las asociaciones faunísticas exhumadas en CdM serán comunicadas en futuros trabajos. De acuerdo a Cione y Tonni $(1995,2005)$ las unidades cronoestratigráficas pampeanas encuentran su fundamento en la determinación de unidades bioestratigráficas. Por lo cual sin la determinación de las últimas no podremos inferir las primeras. No obstante, de acuerdo a los datos disponibles sobre magnetoestratigrafía, dataciones radiométricas y correlaciones ampliamente aceptadas podemos efectuar, al menos preliminarmente, una asignación cronoestratigráfica y geocronológica a la sucesión sedimentaria de CdM: 
- Detección de un evento de polaridad inversa en la Lf D (Heil et al., 2002; Soibelzon et al., 2009), es decir que esta entidad se habría depositado en una edad más antigua que $780 \mathrm{ka}$ AP.

- Asignación de las AF 2-3 y Lf $\mathrm{N}$ al cron de polaridad normal Brunhes, y por lo tanto más joven que 780 ka AP (Heil et al., 2002; Soibelzon et al., 2009).

- Datación ${ }^{40} \mathrm{Ar} /{ }^{39} \mathrm{Ar}$ sobre vidrios de impacto provenientes de la Lf G (Schultz et al., 2004) arrojaron una edad mínima de en $230 \pm 30$ ka AP.

- Correlación de la Lf L y M con facies similares de Claromecó portadoras de Tegula patagonica cuya U/Th arrojó una edad de 93,5 $\pm 3,5 \mathrm{ka}$ AP (= interglacial Sangamoniano, estadío isotópico 5e, circa 120 ka AP; Isla et al., 2001).

- Correlación de la Lf N con la Formación La Postrera, cuya depositación se habría iniciado circa 20-19 ka AP (Sayago, 1995; Sayago, et al., 2001; Smith et al., 2003).

De acuerdo a los datos expuestos y las edades estipuladas por el esquema crono-bioestratigráfico propuesto por Cione y Tonni (2005) la AF 1 correspondería al Piso/Edad Ensenadense (Pleistoceno Inferior-Medio) o pisos/edades inferiores (más antiguo que $780 \mathrm{ka} \mathrm{AP).} \mathrm{En} \mathrm{tanto,} \mathrm{la} \mathrm{AF} 2$ sería asignable al la parte más alta del Piso/Edad Bonaerense (intervalo geocronológico 230-120 ka AP, Pleistoceno Medio superior). La AF 3 podría ser referida a la parte mas baja del Piso/Edad Lujanense (circa 120 ka AP, Pleistoceno Superior inferior) muy cercano al límite Lujanense-Bonaerense (véase Pardiñas et al. 1996; Cione \& Tonni, 1999). Finalmente, si correlacionamos a la Lf N con la Formación La Postrera, esta entidad habría comenzado a depositarse circa 20-19 ka AP correspondiendo a la parte cuspidal del Piso/Edad Lujanense (Pleistoceno Superior superior-Holoceno Inferior) o al Piso/Edad Platense (Holoceno).

\section{AGRADECIMIENTOS}

A C. Larriestra por apoyar de múltiples maneras el inicio de los trabajos en CdM, U.F.J. Pardiñas y M. González por sus valiosos comentarios de campo, L. Rey por su colaboración en las tareas y observaciones de campo, G. Scillato-Yané, F. Islas, familia de los Reyes, Silvio Lorenzini, Carlos Canelo y familia, Museo Rincón del Indio (CdM), L. Marti por su ayuda en la traducción del resumen y a N. Davini por su enorme paciencia. El manuscrito preliminar fue sustancialmente mejorado gracias a los comentarios y sugerencias gentilmente vertidos E.P. Tonni, M. Zárate y E. Soibelzon. Agradezco muy especialmen- te a M.L. de los Reyes su fundamental contribución a la versión preliminar de este trabajo y por los años de estudio compartidos en CdM.

Este es un aporte al proyecto UNLP 1000-03215-2005.

\section{Referencias}

Aguirre, M.L. \& Whatley, R.C. (1995). Late Quaternary marginal marine deposits and palaeoenvironments from northeastern Buenos Aires Province, Argentina: A review. Quaternary Science Reviews, 14: 223-254. doi:10.1016/02773791(95)00009-E

Ameghino, F. (1889). Contribución al conocimiento de los mamíferos fósiles de la Republica Argentina. Actas de la Academia Nacional de Ciencias de Córdoba 6, 1028 pp.

Bargo, S.M.; Vizcaíno, S.F.; Archuby, F.M. \& Blanco, R.E. (2000). Limb bone proportions, strength and digging in some lujanian (Late Pleistocene-Early Holocene) Mylodontid ground sloths (Mammalia, Xenarthra). Journal of Vertebrate Paleontology, 20: 601-610. doi: 10.1671/02724634(2000)020[0601:LBPSAD]2.0.CO;2

Bergqvist, L.P. \& Maciel, L. (1994). Icnofósseis de mamiferos (crotovinas) na planicie costeira do Rio Grande do Sul, Brasil. Annais da Academia Brasileira de Ciencias, 52: 359-377.

Bogan, S.; de los Reyes, L.M. \& Cenizo, M.M. (2006). Primer registro del genero Jenynsia Gunther, 1866 (Teleostei: Cyprinodontiformes) en el Pleistoceno Medio tardío de la provincia de Buenos Aires (Argentina). Papéis Avulsos de Zoologia, 49: 81-86.

Bond, M. \& Massoia, E. (1981). La presencia de Holochilus magnus (Rodentia, Cricetidae) en el Pleistoceno superior de la provincia de Buenos Aires. Circular Informativa, Asociación Paleontológica Argentina, 8: 11.

Cenizo, M.M. \& Ibañez, M.B. (2006). Primer registro para el género Oxyura Bonaparte, 1928 (Anatidae, Anseriformes) en el Pleistoceno Medio-Tardío de la provincia Buenos Aires. Ameghiniana, 43: 29R.

Cenizo, M.M. \& Agnolin, F. (2007). La presencia del género Belonopterus Reichenbach, 1852 (Aves, Charadriidae) en el Pleistoceno de Argentina, con la descripción de Belonopterus lilloi nov. sp. Revista del Museo Argentino de Ciencias Naturales, 9: 41-47.

Cenizo, M.M. \& de los Reyes, L.M. (2008). Primeros registros de Tyto alba (Scopoli, 1769) (Strigiformes, Aves) en el Pleistoceno Medio-Tardío de la provincia de Buenos Aires (Argentina) y sus implicancias tafonómicas. Revista del Museo Argentino de Ciencias Naturales, 10: 199-209.

Cione, A.L. \& Tonni, E.P. (1995). Chronostratigraphy and «Land-mammal ages» in the Cenozoic of Southern South America: Principles, practices and the «Uquian» problem. Journal of Paleontology, 69: 135-159.

Cione, A.L. \& Tonni, E.P. (1999). Biostratigraphy and chronological scale of uppermost Cenozoic in the Pampean area, Argentina. In: Quaternary of South America and Antarctic Peninsula, 3 (Rabassa, J. \& Salemme, M.C., eds.), 23-52. 
Cione, A.L. \& Tonni, E.P. (2005). Bioestratigrafía basada en mamíferos del Cenozoico superior de la región pampeana. In: Geología y Recursos Minerales de la Provincia de Buenos Aires (de Barrio, R.; Etcheverry, R.O.; Caballé, M.F. \& Llambías, E., eds.). XVI Congreso Geológico Argentino, La Plata, Relatorio 11, 183-200.

Codignotto, J.O. \& Kokot, R.R. (2005). Geomorfología del sector litoral de la provincia de Buenos Aires. XVI Congreso Geológico Argentino, 3: 643-650.

Daino, L. (1979). Exégesis histórica de los hallagos arqueológicos de la costa atlántica bonaerense. Prehistoria Bonaerense, 95-195.

De los Reyes, L.M; Cenizo, M.M.; Agnolin, F.; Lucero, S.; Bogan, S.; Lucero, R.; Pardiñas, U.F.J.; Prevosti, F. \& Scanferla, A. (2006a). Aspectos paleofaunísticos y estratigráficos preliminares de las sucesiones pliopleistocénicas de la localidad Centinela del Mar, provincia de Buenos Aires, Argentina. $9^{\circ}$ Congreso Argentino de Paleontología y Bioestratigrafía, 105.

De los Reyes, L.M.; Cenizo, M.M. \& Lorenzini, S. (2006b). Restos de Sclerocalyptus en una paleocueva ¿Evidencias de reocupación o posible constructor?. IX Congreso Argentino de Paleontología y Bioestratigrafía, 280.

Fidalgo, F.; De Francesco, F. \& Colado, U. (1973a). Geología superficial de las hojas de Castelli, Cobo y Monasterio (provincia de Buenos Aires). V Congreso Geológico Argentino, 4: 27-30.

Fidalgo, F.; De Francesco, F. \& Colado, U. (1973b). Sobre ingresiones marinas cuaternarias en 1 os partidos de Castelli, Chascomús y Magdalena (provincia de Buenos Aires). V Congreso Geológico Argentino, 3: 227-240.

Fidalgo, F.; De Francesco, F. \& Pascual, R. (1975). Geología superficial de la llanura Bonaerense. Relatorio VI Congreso Geológico Argentino, 103-138.

Fidalgo, F.; Riggi, J.C.; Gentile, R.; Correa, H. \& Porro, N. (1991). Los «sedimentos postpampeanos» continentales en el ámbito sur bonaerense. Revista de la Asociación Geológica Argentina, 46: 239-256.

Frenguelli, J. (1921). Los terrenos de la costa atlántica en los alrededores de Miramar (provincia de Buenos Aires) y sus correlaciones. Boletín de la Academia Nacional de Ciencias, 24: 325-485.

Frenguelli, J. (1928). Observaciones geológicas en la región costanera sur de la provincia de Buenos Aires. Anales de la Facultad de Ciencias de la Educación, 2: 1-145.

Frenguelli, J. (1950). Rasgos generales de la morfología y geología de la provincia de Buenos Aires. LEMIT, 2: 33.

Frenguelli, J. (1955). Loess y limos pampeanos. Anales Sociedad Argentina de Estudios Geográficos, 1: 1-88.

Fryklund, B.; Marshall, A. \& Stevens, J. (1996). Cuenca del Colorado. In: Geología y Recursos Naturales de la Plataforma Continental Argentina (Ramos, V.A. \& Turic, M.A., eds.). Relatorio XIII Congreso Geológico Argentino y III Congreso de Explotación de Hidrocarburos (Buenos Aires), 8: 135-158.

Genise, J.F. (1989). Las cuevas con Actenomys (Rodentia, Octodontidae) de la Formación Chapadmalal (Plio- ceno Superior) de Mar del Plata y Miramar (Provincia de Buenos Aires). Ameghiniana, 26: 33-42.

Heil, C.; King, J.; Zárate, M.A. \& Schultz, P.H. (2002). Paleomagnetic and environmental magnetic studies of Pampeano Loess Deposits from Centinela del Mar, Argentina. EOS Trans. AGU Suppl. 83 GP71A-0974

Imbellone, P. \& Teruggi, M. (1988). Sedimentación crotovínica en sucesións cuaternarias bonaerenses. II Reunión Argentina de Sedimentología, 125-129.

Imbellone, P.; Teruggi, M. \& Mormeneo, L. (1990). Crotovinas en sedimentos Cuaternarios del partido de La Plata. International Symposium on Loess, CADIQUA, 166-172.

Isla, F.I.; Cortizo, L.C. \& Schnack, E.J. (1996). Pleistocene and Holocene beaches and estuaries along the southern barrier of Buenos Aires, Argentina. Quaternary Science Reviews, 15: 833-841. doi:10.1016/S02773791(96)00065-0

Isla, F.I.; Rutter, N.W.; Schanck, J.E. \& Zárate, M.A. (2000). La transgresión belgranense en Buenos Aires. Una revision a cien años de su definición. Revista Cuaternario y Ciencias Ambientales, 1: 3-14.

Kraglievich, J.L. (1952). El perfil geológico de Chapadmalal y Miramar, Provincia de Buenos Aires. Revista del Museo Municipal Ciencias Naturales y Tradicional de Mar del Plata, 1: 8-37.

Kraglievich, J.L. (1959). Nota acerca de la geología costera en la desembocadura del arroyo Malacara (prov. de Buenos Aires). Revista del Museo Argentina de Ciencias Naturales, 1: 3-9.

Laza, J.H. (1995). Signos de actividad de insectos. In: Evolución biológica y climática de la región pampeana durante los últimos cinco millones de años. Un ensayo de correlación con el Mediterraneo Occidental (Alberti, M.T.; Leone, G. \& Tonni, E.P., eds.). Monografía 12, Museo Nacional de Ciencias Naturales. Madrid, 341- 361.

Marcomini, S.C. \& Lopez, R.A. (2005). Morfodinámica costera entre Punta Florida y Costa Bonita, provincia de Buenos Aires. XVI Congreso Geológico Argentino, 3: 553-558.

Miall, A.D. (2000). Principles of Sedimentary Basin Analysis. Third edition, Springer, $616 \mathrm{pp}$.

Orgeira, M.J. (1988). Estudio paleomagnético de sedimentos del Cenozoico tardío en la costa atlántica bonaerense. Revista de la Asociación Geológica Argentina, 42: 362-376.

Pardiñas, U.F.J.; Gelfo, J.; San Cristóbal, J.; Cione; A.L. \& Tonni; E.P. (1996). Una tafocenosis de organismos marinos y continentales en el Pleistoceno superior en el sur de la provincia de Buenos Aires. $13^{\circ}$ Congreso Geológico Argentino y $3^{\circ}$ Congreso de Exploración de Hidrocarburos, 5: 95-111.

Parodi, L.J. \& Parodi Bustos, R. (1952). Apuntes para geología de la costa atlántica de la Provincia de Buenos Aires, con descripción de la Formación de Malacara. Anales de la Sociedad Científica Argentina, 153: 139-156.

Pascual, R.; Ortega Hinojosa, E.; Gondar, O. \& Tonni, E. (1965). Las Edades del Cenozoico Mamalífero de la Argentina con especial atención a aquellas del territo- 
rio bonaerense. Anales de la Comisión de Investigaciones Científicas de la Provincia de Buenos Aires, 6:165-193.

Quintana, C.A. (1992). Estructura interna de una paleocueva, posiblemente de un Dasypodidae (Mammalia, Edentata), del Pleistoceno de Mar del Plata (provincia de Buenos Aires, Argentina). Ameghiniana, 29: 87-91.

Reading, H.G. \& Levell, B.K. (1996). Controls on the sedimentary rock record. In: Sedimentary Environments: Processes, Facies and Stratigraphy (Reading, H.G., ed.). Blackwell Science, 5-36 pp.

Rolleri, E.O. (1975). Provincias geológicas bonaerenses. Relatorio VI Congreso Geológico Argentino, 29-53.

Roth, S. (1920). Investigaciones geológicas en la llanura pampeana. Revista del Museo de La Plata, 25: 135-342.

Roucco, M. (1989). A 3 Ma paleomagnetic record of coastal continental deposit in Argentina. Palaeogeography, Palaeoclimatology, Palaeoecology, 72: 105113. doi:10.1016/0031-0182(89)90135-1

Sayago, J.M. (1995). The Argentine neotropical loess: An overview. Quaternary Science Reviews, 14: 755766. doi:10.1016/0277-3791(95)00050-X

Sayago, J.M.; Collantes, M.M.; Karlson, A. \& Sanabria J. (2001). Genesis and distribution of the Late Pleistocene and Holocene loess of Argentina: a regional approximation. Quaternary Science Reviews, 76: 247-257.

Scanferla, C.A.; de los Reyes, L.M. \& Cenizo, M.M. (2005). Primer registro fósil del género Lystrophis (Ophidia-Colubridae-Xenodontinae). Stvdia Geologica Salmanticensia, 41: 93-101.

Schultz, P.H.; Zárate, M.A.; Hames, B.; Koeberl, C.; Bunch, T.; Storzer, D.; Renne, P. \& Wittke, J. (2004). The Quaternary impact record from the Pampas, Argentina. Earth and Planetary Sciences Letters, 219: 221-238. doi:10.1016/S0012821X(04)00010-X

Smith, J.; Vance, D.; Kemp, R.A.; Archer, C.; Toms, P.; King, M. \& Zárate, M. (2003). Isotopic constraints on the source of Argentinian loess - with implications for atmospheric circulation and the provenance of Antarctic dust during recent glacial maxima. Earth and Planetary Science Letters, 212: 181-196. doi:10.1016/ S0012-821X(03)00260-7

Soibelzon, E.; Prevosti, F.J.; Bidegain, J.C.; Rico, Y.; Verzi, D.H. \& Tonni, E.P. (2009). Correlation of Cenozoic sequences of southeastern Buenos Aires province: biostratigraphy and magnetostratigraphy. Quaternary International, 210: 51-56. doi:10.1016/j. quaint.2009.06.030

Soibelzon, E.; Zurita, A.E. \& Carlini, A.A. (2006). Glyptodon munizi Ameghino (Mammalia, Cingulata, Glyptodontidae): redescripción y anatomía. Ameghiniana, 43: 377-384.

Teruggi, M.E. (1957). The nature and origin of Argentine loess. Journal of Sedimentary Petrology, 27: 322-332.

Teruggi, M.E., Andreis, R.H.; Mazonni, M.M.; Dalla Salda, L.H. \& Spalletti, L.A. (1974). Nuevos criterios para la estratigrafía del Cuaternario de las barrancas de Mar del Plata-Miramar. LEMIT, 2: 134-148.

Tonni, E.P. \& Fidalgo, F. (1982). Geología y Paleontología de los sedimentos del Pleistoceno en el área de
Punta Hermengo (Miramar, Prov. de Buenos Aires, Rep. Argentina): Aspectos Paleoclimáticos. Ameghiniana, 19: 79-108.

Tonni, E.P.; Prado, J.L.; Menegaz, A.N. \& Salemme, M.C. (1985). La Unidad Mamífero (Fauna) Lujanense. Proyección de la Estratigrafía mamaliana al Cuaternario de la región pampeana. Ameghiniana, 22: 255-261.

Tonni, E.P.; Bergman, W.D.; Fidalgo, F.; Goin; F.J. \& Quiroga, J.C. (1987). La Fauna Local Centinela de Mar y una nueva Unidad Mamífero para el Pleistoceno Tardío de la provincia de Buenos Aires (Argentina). $X$ Congreso Geológico Argentino, 3: 175-177.

Torres, L.M. \& Ameghino, C. (1913a). Informe preliminar sobre las investigaciones geológicas y antropológicas en el litoral marítimo sur de la provincia de Buenos Aires. Revista del Museo de La Plata, 20: 151-167.

Torres, L.M. \& Ameghino, C. (1913b). Investigaciones geológicas y antropológicas en el litoral marítimo sur de la provincia de Buenos Aires. Physis, 5: 261-264.

Violante, R.A. \& Parker, G. (1992). Estratigrafía y rasgos evolutivos del Pleistoceno medio a superior-Holoceno en la llanura costera de la región de Faro Querandí (Provincia de Buenos Aires). Revista de la Asociación Geológica Argentina, 47: 215-228.

Vizcaíno, S.F.; Zárate, M.A.; Bargo M.S. \& Dondas, A. (2001). Pleistocene burrows in the Mar del Plata area (Argentina) and their probable builders. Acta Palaeontologica Polonica, 46: 289-301.

Yrigoyen, M. (1975). Geología del subsuelo y la plataforma continental. Relatorio VI Congreso Geológico Argentino, 139-168.

Zambrano, J.J. (1972). Cuenca del Colorado. In: Geología Regional Argentina (Leanza, A.F., ed.). Academia Nacional de Ciencias, 419-437.

Zárate, M.A. (1989). Estratigrafía y geología del Cenozoico Tardio en los acantilados marinos comprendidos entre Playa San Carlos y Arroyo Chapadmalal. Pdo. Gral. Pueyrredón, Prov. de Bs. As. Tesis Doctoral, Facultad de Ciencias Naturales y Museo, Universidad Nacional de La Plata, 221 pp.

Zárate, M.A. (2005). El Cenozoico tardío continental de la Provincia de Buenos Aires. In: Geología y Recursos Minerales de la Provincia de Buenos Aires (de Barrio, R.E.; Etcheverry, R.O.; Caballé, M.F. \& Llambías, E., eds.). Relatorio XVI Congreso Geológico Argentino, 8: 139-158.

Zárate, M. \& Blasi, A. (1993). Late Pleistocene-Holocene aeolian deposits of the southern Buenos Aires Province, Argentina: a preliminary model. Quaternary Science Reviews, 17: 15-20.

Zárate, M.A. \& Rabassa, J. (2005). Geomorfología de la Provincia de Buenos Aires. In: Geología y Recursos Minerales de la Provincia de Buenos Aires (de Barrio, R.E.; Etcheverry, R.O.; Caballé, M.F. \& Llambías, E., eds.). Relatorio XVI Congreso Geológico Argentino, 8: 119-138.

Recibido el 15 de abril de 2010 Aceptado el 20 de octubre de 2010 Publicado online el 5 de mayo de 2011 